\title{
Increasing Flight Endurance of MAVs using Multiple Quantum Well Solar Cells
}

\author{
Mostafa Hassanalian*, Mohammadreza Radmanesh and Ahmad Sedaghat \\ Department of Mechanical Engineering, Isfahan University of Technology (IUT), Isfahan 84156-8311, Iran
}

\begin{abstract}
Micro Aerial Vehicles (MAVs) are useful devices to assess new features that may be utilized in a full size aircraft to enhance performance or to increase endurance. In this article, sources for energy saving in the micro air vehicles are initially addressed. Then, by specifying the important parameters on energy consumption of an aircraft, a feasibility study is conducted to assess the benefit of using solar cells to increase flight endurance. Next, a new solar cell has been designed and optimized for MAVs. This cell consists of a multiple quantum wells for which the quantum factor and the absorption coefficient are calculated by solving the Shrodinger equation using MATLAB software. Then, the manner and influence of MAVs parameters using the solar cells are examined to suggest optimal planform for different purposes. In order to increase flight endurance, it is noted that by using appropriate planform and the optimized solar cells, flight endurance can be increased by more than 30 percent.
\end{abstract}

Key words: Micro Air Vehicle, Hybrid energy, Endurance, Solar cell, Quantum well.

\section{Introduction}

The idea of using solar cells in aircraft and even spacecraft has been considered for many years, and a lot of research has been done on construction. However, the fairly low efficiency of first generation solar cells was limited using these cells as an energy source. With the advent of new generation, solar cells with higher absorption the usefulness in small devices such as MAVs is growing. These micro air vehicles (MAVs), referred to the drones, are less than 500 millimeters and weight under 500 grams. These usually use one of four types of wings; fixed wing, VTOL wing, flapping wing, and rotary wings. Depending on the flight mission, the size and type of equipment installed on a MAV is different. The remarkable benefits of MAVs led to research to optimize and enhance the capabilities of these air vehicles. Remote control capability is important when it is difficult, impossible, or dangerous for a human being to be present. According to the characteristics mentioned, MAVs have the potential to perform a variety of reconnaissance, patrol, and protection tasks, and carry small loads of less than 10 grams, such as sensors. Also with installation of sensors on the aircraft, conditions such as temperature and pressure are measurable. The first comprehensive research was conducted on MAVs by the RAND institute in 1993. Today, a broad spectrum of research activities in this field are ongoing with the aim of making of MAVs smaller than 15 centimeters and that have the ability for doing reconnaissance and rescue missions. Such aircraft, in addition to being small, fly with low speeds. In figure 1 different types of micro air vehicles are shown [1-2].

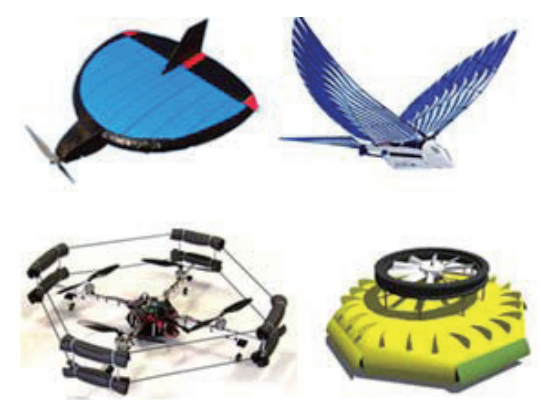

Fig. 1. Different types of MAVs
This is an Open Access article distributed under the terms of the Creative Commons Attribution Non-Commercial License (http://creativecommons.org/licenses/by$\mathrm{nc} / 3.0 /$ ) which permits unrestricted non-commercial use, distribution, and reproduction in any medium, provided the original work is properly cited. 


\section{MAV Power Resources}

Aircraft power is provided from various fossil fuel sources. Fossil fuels are for the main energy supply for manned aircraft and unmanned MAVs. But, in aircrafts with small dimensions, particularly in MAVs, the power for the plane flight is provided by battery. Over 90 percent of these aircraft utilize Li-PO batteries. Sometimes, some fossil fuels such as gasoline or alcohol are used for powering jet propulsion. For general MAVs, lithium batteries are the best choice due to their low weight. Fossil fuels are capable of producing more energy than batteries, but the efficiency of available internal combustion engines for use in these micro air vehicles is extremely low. In addition reducing the weight of the aircraft as fuel is used causes stability problems in these micro air vehicles. One of the with currently available micro air vehicles is that at maximum flight time is between 20 and 30 minutes with using battery or fuel [3].

The interest level in development of fixed wing MAV aircraft for different missions has increased recently. One crucial problem is that they possess limited endurance in comparison with larger aircrafts. Today, high endurance flight is a great advantage in any mission. One issue is that the micro air vehicles have limited storage capacity. Flight time of an MAV depends on the power resource and electricity consumption. This has limited the flight endurance up to 30 minutes. Although, the micro fuel cell is under development, this technology is yet to be used in MAVs. Today, small lithium polymer batteries are more in demand in the market. In table 1, the features of four types of batteries are compared, showing that lithium batteries are the best choices [4].

\section{Reducing MAV power consumption}

A variety of parameters are involved in reducing power consumption in a MAV including plan form shape, cruise speed, wing span, airfoil type, and weather conditions.

Table 1. Comparison of batteries with their specific energy, energy density, and specific power

\begin{tabular}{|l|c|c|c|c|}
\hline & Ni-Cd & Ni-Mh & Li-Po & Li-S \\
\hline $\begin{array}{l}\text { Specific } \\
\text { Energy } \\
\text { (Wh/kg) }\end{array}$ & 40 & 80 & 180 & 350 \\
\hline $\begin{array}{l}\text { Energy } \\
\text { Density } \\
\text { (Wh/l) }\end{array}$ & 100 & 300 & 300 & 350 \\
\hline $\begin{array}{l}\text { Specific } \\
\text { Power } \\
\text { (W/kg) }\end{array}$ & 300 & 900 & 2800 & 600 \\
\hline
\end{tabular}

Aircraft drag reduction is one of the main factors for increasing the flight endurance. Parameters that can be optimized to reduce drag are the geometric parameters such as plant form, airfoil, aspect ratio, and wing length. Each of the geometric parameters and design choices should be considered to reduce the drag of an aircraft. For example, the plan form and aspect ratio at a certain level may lead to a minimum of drag during flight. In Fig. 2, several planforms including Zimmerman plan form, inverse Zimmerman, CRI, and inverse CRE are shown. Table 2 shows a comparison of the aspect ratio of 1 to 2 and lift and drag values of these plan forms. All aerodynamic coefficients were obtained using XFLR5 software, an aerodynamic analysis tool.

Comparing different aspect ratios of 1, 1.25, 1.5, 1.75 and 2, the following conclusions can be drawn. For aspect ratio 1, inv- CRE and CRE plan forms are more efficient than Zimmerman plan form. CRE and INV-CRE have less drag than inverse Zimmerman. CRE plan forms and invCRE are more efficient than Zimmerman. CRE plan form has a minimal drag. CRE plan form has the lowest drag in

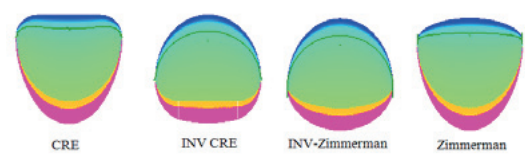

Fig. 2. Four plan form configurations used in MAVs.

Table 2. Comparison of the CRE, Zimmerman plan-forms and the inversed shapes

\begin{tabular}{|c|c|c|c|c|c|c|}
\hline $\mathrm{AR}$ & Coefficient & CRE & Inv- CRE & Zim & Inv-Zim & $\left.\mathrm{C}_{\mathrm{D}}\right) / \mathrm{Max} \alpha\left(\mathrm{C}_{\mathrm{L}}\right.$ \\
\hline \multirow{3}{*}{1} & $\mathrm{C}_{\mathrm{L}}$ & 3 & 2 & 4 & 1 & \multirow{3}{*}{6} \\
\hline & $C_{D}$ & 3 & 2 & 4 & 1 & \\
\hline & $\mathrm{C}_{\mathrm{D}} / \mathrm{C}_{\mathrm{L}}$ & 3 & 2 & 4 & 1 & \\
\hline \multirow{3}{*}{1.25} & $\mathrm{C}_{\mathrm{L}}$ & 4 & 2 & 3 & 1 & \multirow{3}{*}{5} \\
\hline & $\mathrm{C}_{\mathrm{D}}$ & 4 & 2 & 3 & 1 & \\
\hline & $\mathrm{C}_{\mathrm{D}} / \mathrm{C}_{\mathrm{L}}$ & 3 & 2 & 4 & 1 & \\
\hline \multirow{3}{*}{1.5} & $\mathrm{C}_{\mathrm{L}}$ & 4 & 2 & 3 & 1 & \multirow{3}{*}{4} \\
\hline & $\mathrm{C}_{\mathrm{D}}$ & 4 & 2 & 3 & 1 & \\
\hline & $\mathrm{C}_{\mathrm{D}} / \mathrm{C}_{\mathrm{L}}$ & 4 & 2 & 3 & 1 & \\
\hline \multirow{3}{*}{1.75} & $\mathrm{C}_{\mathrm{L}}$ & 4 & 2 & 3 & 1 & \multirow{3}{*}{4} \\
\hline & $\mathrm{C}_{\mathrm{D}}$ & 4 & 2 & 3 & 1 & \\
\hline & $\mathrm{C}_{\mathrm{D}} / \mathrm{C}_{\mathrm{L}}$ & 4 & 2 & 3 & 1 & \\
\hline \multirow{3}{*}{2} & $\mathrm{C}_{\mathrm{L}}$ & 4 & 3 & 2 & 1 & \multirow{3}{*}{3} \\
\hline & $\mathrm{C}_{\mathrm{D}}$ & 4 & 3 & 2 & 1 & \\
\hline & $\mathrm{C}_{\mathrm{D}} / \mathrm{C}_{\mathrm{L}}$ & 4 & 2 & 3 & 1 & \\
\hline
\end{tabular}


the aspect ratio of 1.5, and INV-CRE plan form has more efficiency than Zimmerman. In an aspect ratio of 1.75, INVCRE plan form is more efficient than Zimmerman plan form and CRE plan form has the minimal drag. In an aspect ratio of 2, CRE and INV-CRE plan forms have less drag and INVCRE plan form has greater efficiency than Zimmerman plan form. Among the above plan forms, the reverse Zimmerman is the best choice in term of efficiency and CRE plan form is recommended for the lowest drag. Thus, this latter shape is the best choice because the drag is the lowest which assist in providing longer endurance. So, it can be concluded that typical plan forms influence the power consumption of an aircraft. Fig. 3 shows the battery capacity against wing span at different wing areas [5-6].

As seen in Fig. 3, increasing surface area and wing span requires higher battery capacity storage.

\section{The use of solar cells in drones}

One possible energy sources for enhancing flight endurance is solar power. The first flight with using solar cells occurred in November, 1974 by the Astroflight Sunrise airplane in California. The next solar plane named the Gossamer Penguin flew in 1980. Other examples of unmanned aircrafts were the Centurion, the Pathfinder, and the Helios. As noted above, the increased use of unmanned aircraft in different missions ranging from military to civil, during recent years has been made possible by engineers who have optimized the performance of these air vehicles. One issue limiting micro air vehicles is the high power consumption and the limited power capacity due to weight limitations. A common method used to increase flight endurance is the use of solar energy. Solar cells are an unlimited energy source that can be used for engines and other systems. An electronic circuit may be necessary for the engine and other electronic devices to draw power from solar cells and to recharge the battery, which is used as a backup

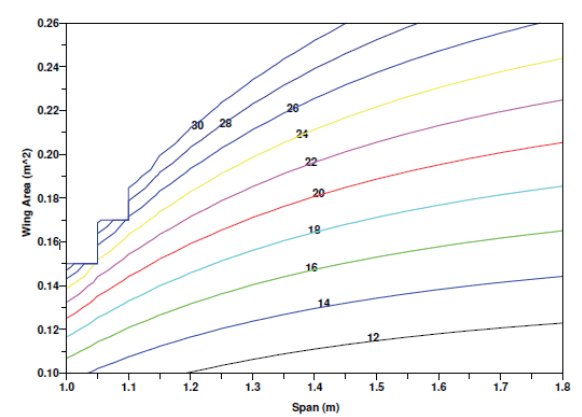

Fig. 3. Required battery capacity (Ah) for MAVs with indicated wingspan and wing area in $20 \mathrm{~m} / \mathrm{s}$ cruise speed when the solar cells cannot produce enough power flying under clouds or in the dark. In other words, the combination of solar cells and batteries might provide a hybrid source that can be used for powering MAVs. As shown in figure 4, solar cells convert solar energy into electrical energy to be used by an electric motor [7].

Today, with the recent developments and the emergence of flexible and thin solar cells, it has changed the landscape and made solar power a reality.

\section{Aircraft design with solar cells}

Nowadays, solar cells are thin, flexible, low weight, and efficient and can be used in small Unmanned Aerial Vehicles (UAVs).

Many examples exist for solar energy use in UAV. But today a notable example, which is close to micro UAV dimensions, is the Silver Sky aircraft which has a flight endurance of about 2 hours. Hence, the use of solar energy is reality in MAVs with a wing span of 0.77 meter or higher. Solar cells usually cover the surface of the aircraft and when the aircraft is exposed to the sun the cells change the sun's rays into electrical energy. The airplane plan form should be used to allow the most solar cells to be installed. The ratio of the weight of solar cells to electrical equipment used in the MAV is an important parameter when implementing cells. Solar cells on the aircraft must be small sizes, so the ratio will increase overall efficiency. Solar cells are made of silicon. These cells are not suitable to supply enough power to fly, but they can be used for charging batteries. The solar cells must have low weight, be flexible, and have a high efficiency. Thin-Film Solar Cell (TFSC) can be used on a larger surface of the wings and fuselage.

Using thin layers in planes has reduced aerodynamic concerns. Solar cells were never used alone. To prevent battery discharge by solar cells a battery diode is used.

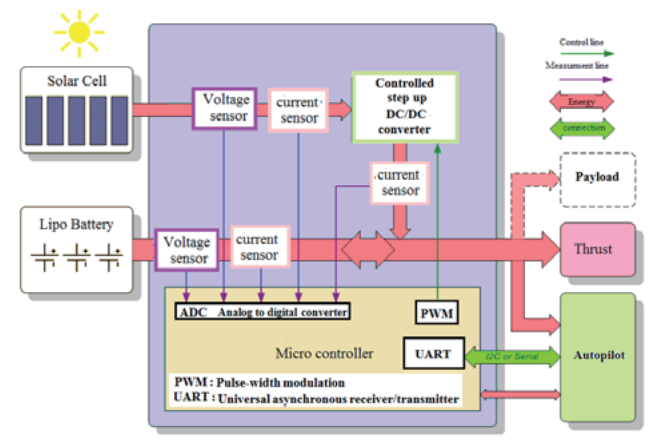

Fig. 4. Diagram used for the usage of hybrid energy in fixed wing MAVs 
One major limitation of solar cells is their high costs, low efficiency, and non-liner response associated with low levels of solar radiation and environmental temperature. One of the parameters that have a great impact on the maximum power output of solar cells is the amount of solar radiation absorbed by the solar cell. To achieve maximum power, you should keep the resistance of solar cells at a maximum. Solar cells current voltage curves show a point with maximum power output. The load on solar cells changes over time and this also affects optimal power. A maximum power cell should be used so that solar cells work with a reasonable level of efficiency and produce optimal power. In fact, the maximum power load tracking on the solar cells can be kept at an optimal position. This detector does this by matching of load impedance with the solar cells internal impedance. So using Maximum Power Point Tracking (MPPT) allows solar cells to exist with highest performance.

Another issue that affect the efficiency of solar cells are temperature; increased temperatures reduce the power output of solar cells. Because the cell's energy production is limited, to achieve the required voltage and current series and parallel combinations of cells are used. Combination of series and parallel cells also improves the system performance when the failure or withdrawal of one or more cells. When the cells are used in series, one cell not in the circuit (due to damage or failure, or restricted light), causes the total energy of the system to hang. Ordering solar cells in series may produce higher voltage. If solar cells are connected in series, they charge the battery directly and almost 10 percent of the solar energy is converted to electricity. If solar cells are connected to the battery, they can supply the engine directly. The use of parallel and range strings and their scalar combinations reduce the possibility of a hot spot and prevent sudden changes of output power (due to the withdrawal of one or more cells.) to limit the adverse effects of ghosting, the parallel connection of barrier diodes at both ends of a cell or group of series cells will be used. In these cells when leaving emergency in the circuit, the diodes will short circuit automatically. In practice, these diodes may be placed in arrays of separate series and the output of a solar array may be connected to

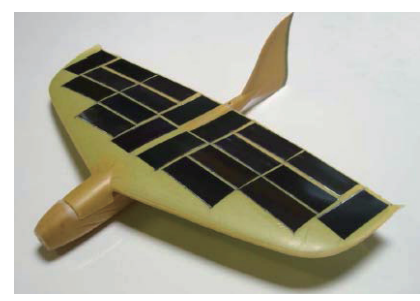

Fig. 5. A solar MAV them.

One of the major issues that concern the arrangement of solar cells is the use of bypass diodes. These diodes are used to deal with the effects of malfunctioning panels. Figure 4 represents a MAV equipped with solar cells.

\section{Optimizing solar cells}

Undoubtedly, in recent decades this has been a rapid transition of volumetric systems to quantum systems with low dimensions in many areas especially in the fields of detectors, lasers, and solar cells. The advantage of such systems such as quantum wells in solar cells is high conversion efficiency, broad spectral response, the ability of these systems to perform and varied designs that can accomodate different parameters. They can be economical, light weight, and easily built with background experience and a long history in the field of semiconductor technology as InGaAs, AlGaAs, and GaAs. Today, among the topics of interest to the scientific community and research in solar cells is debate about optimization of a solar cell's performance with quantum well structure. Because in these structures, there are several free parameters in the design, but changing these parameters cause conflicitng effects on of quantum well solar cells such as absorption, reflection, and photonic current.

\section{Modeling solar cells in a quantum well}

Among the types of structures that exist for solar cells in quantum dimensions, the following scheme is one of the most used collection of multiple quantum wells located in I diode pin empty area and the $\mathrm{P}$ and $\mathrm{n}$ areas made from pure gas. Wells are made of GaAs and the barrier is made of AlGaAs. It should be noted that the diode work in reverse bias.

To optimize the structure of these cells, the quantum calculation is made for finding basic and effective quantity in the parameters of solar cells. The starting point is to solve
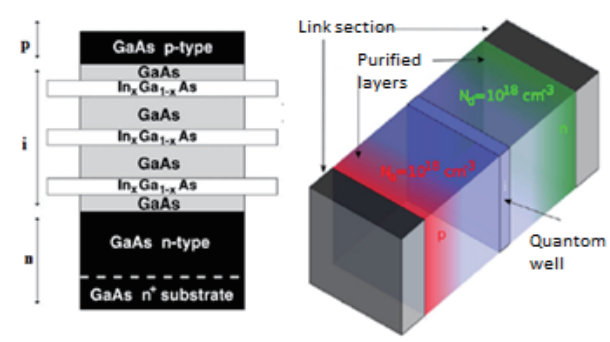

Fig. 6. A solar cell p-i-n quantum well structure 
the Schrodinger equation. This equation is given by (1). This equation is solved for different structures using the finite difference methods or the transfer matrix approach. The first is a numerical and the second is an analytical method. The result of these two methods is completely consistent with each other.

$$
\frac{-h^{2}}{2 m_{j}^{*}} \frac{\partial^{2} \psi_{j}(x)}{\partial x^{2}}+V_{j}(x) \psi_{j}(x)=E \psi_{j}(x)
$$

Solving the above equation, one may obtain the wave function and the energy levels. In solar cells, the quantum wells which are the interval between energy levels determine the maximum absorption wavelength. It is noteworthy that the width and height of the quantum well (the same SDSPAGE extracting the ALGaAs composition) selected in which the distance between the energy levels is in the visible wavelength. In the following Fig. 7, a quantum well and first level wave function is shown.

Wave functions obtained by solving the Schrodinger equation show the impressive power fluctuation which is the most important factor in solar absorption. This quantity is defined by equation (2) in which Me-h is fluctuation power, $\psi \mathrm{e}(\mathrm{z})$ is Electron wave function and $\psi \mathrm{h}(\mathrm{z})$ is the Hole wave function.

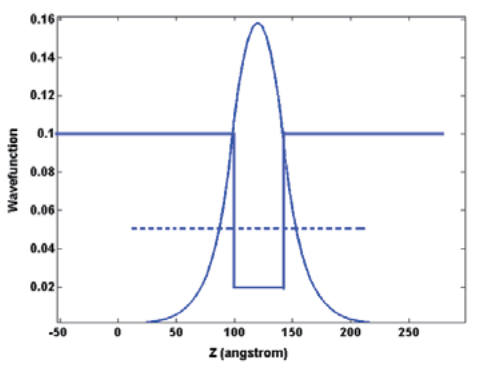

Fig. 7. Energy level and wave function acquired by solving Schrodinger equation for quantum well structure

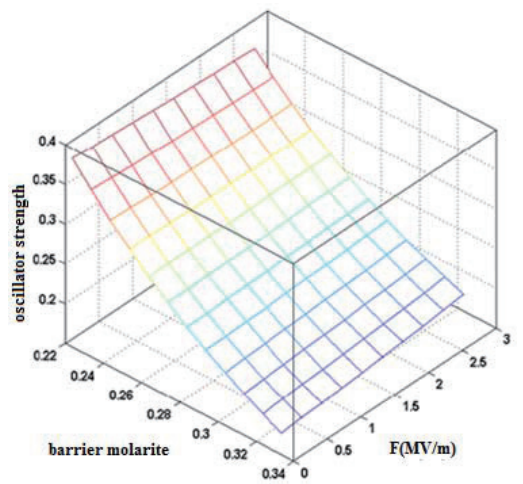

Fig. 8. Fluctuation power dependency on the exerted electric field and SDS-PAGE extracting composition (barrier height)

$$
M_{e-h} \approx\left|\int_{-\infty}^{+\infty} \psi_{e}(z) \psi_{h}(z) d z\right|^{2}
$$

This quantity represents the ability of electrons to absorb. As an example, the dependence of this quantity on two effective parameters is represented in Fig. 8. This figure indicates that with increasing SDS-PAGE extracting, the well will experience a significantly fluctuation power.

Absorption coefficient is one of the factors that affects to solar cell responses. Several factors determining the absorption coefficient including the width of absorption area, the number of periods, and also the fluctuation power. In the model reviewed here, the effective absorption area is the well area, so the width of the barrier and impurities layers will affect absorption. Fig. 9 represents the increase of the well width which it caused an increase in the cell uptake, but in the carriers to transport link section, increasing the width of the well can also increase the risk of carrier impact.

One of the limiting factors that affect the number of periods, the width of well and the barrier is the total length in which the multiple quantum well is located should not be more than about 1.2 micrometer. Another important quantity which is important in solar cell performance is the

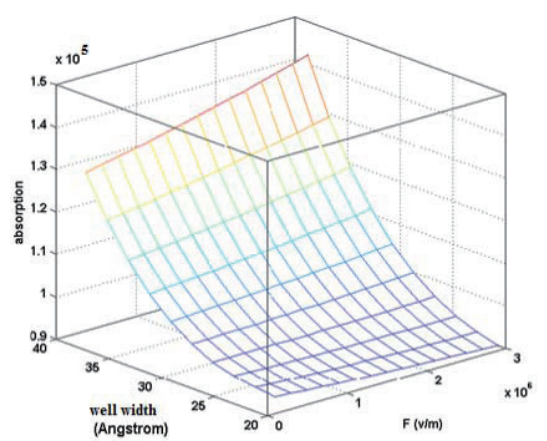

Fig. 9. Absorption coefficient on the exerted electric field and well width

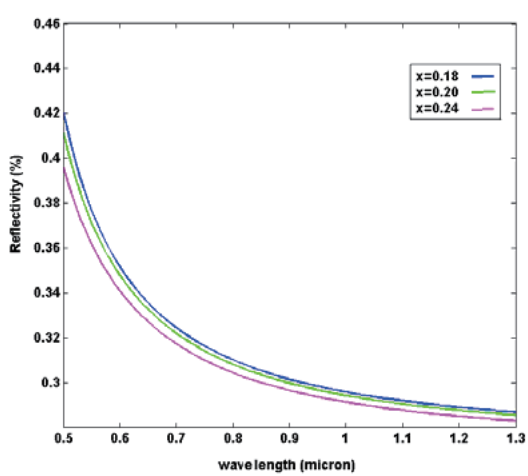

Fig. 10. Dependence of optical reflection coefficient on exerted wavelength for different SDS-PAGE extracting from AIGaAs 
quantum efficiency. This quantity is defined in equation 3.

$$
Q E=(1-R(\lambda)) \times(1-\exp (-N \alpha w))
$$

In the above equation $\mathrm{N}$ is cycles (23 well in a QWSC), $\alpha$ is the absorption coefficient $\left(3^{*} 10^{6}\right)$, and $\mathrm{w}$ is the width of a well (50 Å). In this regard, $\mathrm{R}$ shows the optical reflection of the surface taken (0.2), which depends on wavelength. Figure 10 shows ALGaAs material in several different SDSPAGES extracting from aluminum. The refractive index on wavelength for calculating this diagram is derived from Sellmeier equation. It should be noted that in our calculations, the effects of an anti-reflective coating of $\mathrm{ZnS}$, was investigated which caused a significant increase in response and a decrease of 5 percent reflection.

To calculate the electric current from a solar cell photon (photocurrent), equation (4) can be used.

$$
J_{P H}=q \int F(\lambda) Q E(\lambda) d \lambda
$$

Figure 11 represents $\mathrm{F}$ as a function of the solar spectrum, which was calculated in terms of the Planck distribution function for sun.

As shown in Fig. 9, the maximum absorption is achieved when the well width is 33Å, the barrier SDS-PAGE extracting is $\mathrm{Al} .33 \mathrm{Al} .77 \mathrm{AS}$, and the internal electric field is $30 \mathrm{KV} / \mathrm{cm}$. The quantum efficiency achieved nearly $27 \%$. This means the MAV with flight endurance of 30 minutes can now fly up to 40 minutes using the optimized solar cells. This is more than a 30 percent enhancement of MAV flight endurance.

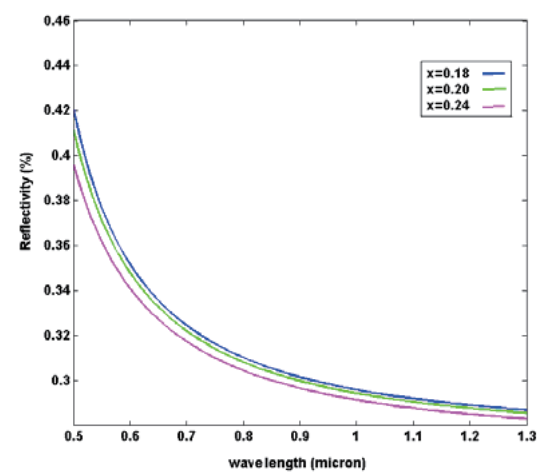

Fig. 11. Function of the solar spectrum

\section{Conclusions}

The new, improved generation of solar cells with high efficiency and great flexibility in drone MAVs can increase endurance by 30 percent. The other effective factors in flight endurance are optimization of size, plan form shape, and cruising speed. The CRE plan form was the optimal plan form in terms of lower drag and higher endurance. The quantum well solar cells, were optimized with a width of $33 \AA$ and barrier SDS-PAGE extracting. The quantum efficiency of this system is near 27 percent. An anti-reflective coating of $\mathrm{ZnS}$ for the solar cells also proved beneficial.

\section{References}

[1] Mueller, T.J., and Kellogg, C., "Introduction to the Design of Fixed-Wing Micro Air Vehicle", American Institute of Aeronautics \& Astronautics, January 1, 2008.

[2] Radmanesh, M., Nematollahi, O., Nili-Ahmadabadi, M., and Hassanalian, M., "A Novel Strategy for Designing and Manufacturing a Fixed Wing MAV for the Purpose of Increasing Maneuverability and Stability in Longitudinal Axis", Accepted in Journal of Applied Fluid Mechanics (JAFM)

[3] Hurd, W.R., 2009. "Application of Copper Indium Gallium Diselenide Photovoltaic Cells to Extend the Endurance and Capabilities of unmanned aerial vehicle", California. Naval Postgraduate School, 2009.

[4] Bronz, M. ,Moschetta, J., “Towards a Long Endurance $M A V$ ", Ecole Nationale de l'Aviation Civile, Toulouse, France, 2009.

[5] André, N., "History of Solar flight". Swiss Federal Institute of Technology, Zürich, July 2008.

[6] André, N., "Design and construction of a solar powered $M A V^{\prime \prime}$, Internship Report, March 2007.

[7] Rimadaa, J.C., and Hernandez, L., "Conversion efficiency enhancement of AlGaAs quantum well solar cells", Microelectronics Journal, Vol. 38, April 2007, pp. 513-518. 